the differentially expressed proteins (red $=$ upregulated, green $=$ downregulated) and proteins that are directly associated to them (white molecules).

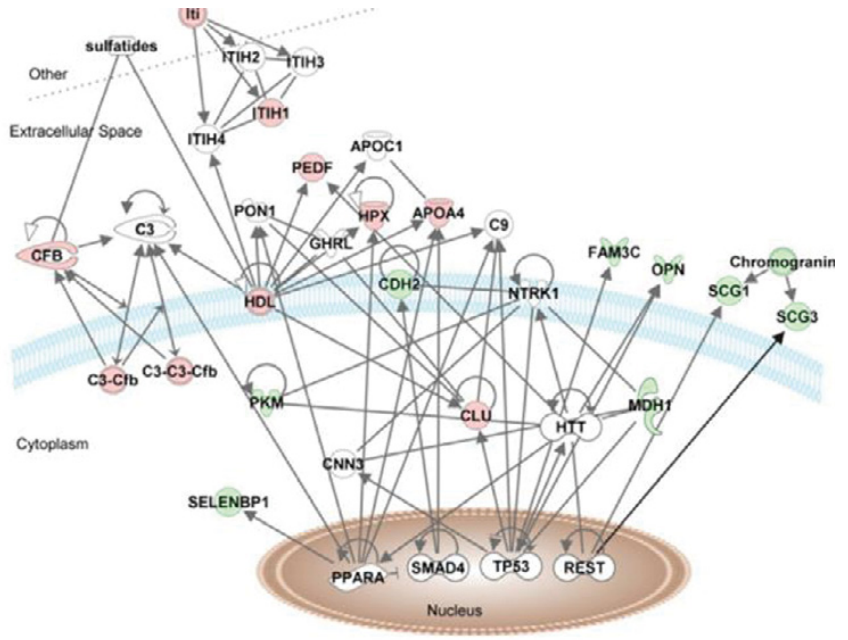

Conclusions: Most of the discriminatory proteins have important roles in regulation of innate immunity, cellular stress defense, and/or functions in the central nervous system. Some have been associated with severe depression and loss of appetite, which are important features of chronic fatigue. These proteins and their interacting protein networks may therefore have central roles in the generation and regulation of fatigue, and the findings add new, relevant, and important evidence to the concept of fatigue as a biological phenomenon signaled through specific molecular pathways.

References:

[1] Norheim KB, Jonsson G, Omdal R. Biological mechanisms of chronic fatigue. Rheumatology (Oxford). 2011;50:1009-18.

[2] Dantzer R, O'Connor JC, Freund GG, Johnson RW, Kelley KW. From inflammation to sickness and depression: when the immune system subjugates the brain. Nature reviews Neuroscience. 2008:9:46-56.

[3] Schutzer SE, Angel TE, Liu T, Schepmoes AA, Clauss TR, Adkins JN, et al. Distinct cerebrospinal fluid proteomes differentiate post-treatment lyme disease from chronic fatigue syndrome. PloS one. 2011;6:e17287.

Disclosure of Interest: None declared

DOI: 10.1136/annrheumdis-2017-eular.3973

\section{OP0313 P75 LOW AFFINITY RECEPTOR OF NERVE GROWTH FACTOR ON PERIPHERAL LEUKOCYTES AND CD11C-POSITIVE DENDRITIC CELLS ARE UPREGULATED IN PATIENTS WITH SYSTEMIC LUPUS ERYTHEMATOSUS}

S. Welle, A.M. Wolf, M.F. Seidel. Medizinische Klinik III, Hematology, Oncology and Rheumatology, University Hospital of Bonn, Bonn, Germany

Background: The nervous system regulates rheumatic diseases in neurogenic inflammation (NI). Nerve growth factor (NGF) plays a pivotal role in $\mathrm{NI}$ and chronic nociceptive pain of degenerative musculoskeletal diseases [1]. Clinical trials using NGF antagonists have shown impressive analgesic efficacy in these disorders [2]. However, the role of NGF in autoimmune inflammatory diseases is not completely understood although $\mathrm{NI}$ perhaps induces and/or mediates disease activity. NGF-receptor expression on peripheral lymphocytes may reflect $\mathrm{NI}$ activity. Objectives: The aim of this study was to identify the expression levels of the NGF receptor with high affinity (TrkA) and low affinity (p75) on leukocyte subsets of SLE patients, as compared to healthy controls (HC).

Methods: The number of TrkA- and p75-positive cells was quantified in 13 SLE patients (diagnosed according to the 1997 ACR revised criteria). CD4, CD8, CD11b, CD11c, CD14, CD16, CD19, CD56 and CD66b antibodies, and isotype controls were used. Cells were quantified by multicolour flow cytometry and compared to gender and age-matched HC $(n=13)$ using the Mann-Whitney-UTest. Values $<0.05$ were considered statistically significant. Patients were further subgrouped for high or low disease activity as determined by SLEDAI, ANA, anti-dsDNA, CRP, complement $\mathrm{C} 3 / \mathrm{C} 4$ and $\mathrm{ESR}$, and compared to $\mathrm{HC}$ using the Kruskal-Wallis test and Mann-Whitney-U-test. NGF serum concentrations were determined by ELISA.

Results: In SLE, TrkA expression on peripheral leukocytes (\%₫SD) was not different from $\mathrm{HC}$ and was highest on CD14+ cells (15.5 \pm 20.6$)$. In contrast, p75 was significantly increased on CD16+ (2.4 \pm 3.0 vs. $0.9 \pm 0.6, p=0.044)$ and CD56+ leukocytes $(1.5 \pm 1.7$ vs. $0.4 \pm 0.3, p=0.022)$ in SLE vs. HC. Further subgroup analyses showed that $\operatorname{Tr} k A(0.6 \pm 0.3$ vs. $1.8 \pm 1.3, \mathrm{p}=0.035)$ and $p 75(0.4 \pm 0.3$ vs. $2.3 \pm 1.8, p=0.014$ ) were decreased on CD56+ cells in patients with high SLEDAI vs. patients with low SLEDAI scores. Similarly, a reduction of $p 75$ on CD19+ B cells was associated with high SLEDAI $(0.8 \pm 0.7$ vs. $10.8 \pm 16.5, p=0.018)$ whereas p75 expression was significantly higher on CD56+ cells in SLE with low SLEDAI as compared to $\mathrm{HC}(2.3 \pm 1.8$ vs. $0.2 \pm 0.2, \mathrm{p}=0.007)$. CD11c+ dendritic cells $(D C)$ did not show differential expression for TrkA or p75, however, they were increased in SLE as compared to $\mathrm{HC}(5.4 \pm 2.5$ vs. $2.5 \pm 0.6, \mathrm{p}=0.0001)$. Interestingly, DC were also significantly elevated in SLE with high SLEDAI, anti-dsDNA, ANA and ESR. NGF serum concentrations did not differ between SLE and HC.

Conclusions: Our data for the first time demonstrate differential NGF receptor expression on an extensive panel of peripheral blood leukocytes in SLE and HC. p75 appears to be the major differentially regulated receptor for NGF. The decrease of TrkA and p75 on CD56+ and p75 on CD19+ cells in patients with high SLEDAl activity is unclear and may reflect a negative feedback mechanism. The increased CD11C+ DC might indicate additional inflammatory activation in SLE. Further studies are needed to analyse these findings.

References:

[1] Seidel MF, Herguijuela M, Forkert R, Otten U. Nerve growth factor in rheumatic diseases. Sem. Arthr. Rheum. 2010; 40(2):109-26.

[2] Seidel MF, Wise BL, Lane NE. Nerve growth factor: an update on the science and therapy. Osteoarthritis Cartilage 2013; 21(9):1223-8.

Disclosure of Interest: None declared

DOI: 10.1136/annrheumdis-2017-eular.2493

\section{FRIDAY, 16 JUNE 2017 Fighting osteoporosis fragilities}

\section{OP0314-HPR A HOME-BASED FALL PREVENTION PROGRAMME REDUCES FEAR OF FALLING IN SENIORS}

B. Zindel ${ }^{1}$, A. Meichtry ${ }^{2}$, V. Krafft ${ }^{1}$, K. Niedermann ${ }^{2} .{ }^{1}$ Swiss League against Rheumatisme, Zurich; ${ }^{2}$ Zurich University of Applied Sciences, Winterthur, Switzerland

Background: Every year, over 80,000 elderly persons in Switzerland have accidents caused by tripping and falling, and half of these falls happen at home or in the direct vicinity (1). Falls, due to its often severe medical consequences and persistent mobility impairments, together with the demographic development, are one of the most important musculo-sceletal problems and public health issue. Falls are often due to a combination of internal risk factors (such as vertigo, osteoporosis, cognitive impairments, decreased ability for dual tasking) and external risk factors (such as medication and environmental risk factors) (2). The Swiss League Against Rheumatism (SLAR) has developed a multidimensional home-based fall prevention programme, which is supported by health insurances. Trained physiotherapists (PTs) and occupational therapists (OTs) visit the seniors at home in order to perform a detailed assessment of the senior's individual risk of falling. Subsequently the PT or OT eliminates identified environmental risk factors and provide tailored exercises. After 4 weeks, a telephone call was made by the PT/OT to discuss unclear instructions and after 16 weeks, follow up data were collected by telephone.

Objectives: The objective was to evaluate the effects of the fall prevention programme.

Methods: A retrospective analysis was carried out on the data of 671 participants in 2015. Available data were participant's characteristics, fall risk factors, determined by the Timed "Up\&Go" with additional motor and cognitive task) (4). Fall Efficacy Scale (5), the recommendations made by the PTs/OTs and satisfaction of the seniors.

Results: The participants were mainly female (62.6\%) and had a mean age of 81.7 years $(S D=5.5$, range $66.1-100$ years). Several risk factors were present: $64.1 \%$ fell at least once in the last year and $45 \%$ were not able to perform a dual task (TUG + additional cognitive task).

Main recommendations made by PTs/OTs were "fixing down of carpets" (56.6\%) and instruction of an exercise programme (strength, balance and multi-task capability) (82.6\%). After four months, fear of falling had decreased (change in FES-I: -1.24 points $95 \% \mathrm{Cl}:(-1.44,-1.04)$, $p$-value $<0.001) .92 \%$ of the participants self-reported to follow the recommendations and $98.4 \%$ were satisfied with the programme and would recommend it to others.

Conclusions: The low-threshold, multidimensional home-based fall prevention developed by the SLAR was feasible and effective. Participants implemented the recommendations and the fear of falling' decreased. Reduced fear of falling is considered a strong predictor of falling, however a prospective study is needed to determine if the reduced fear of falling leads to a decreased number of falls.

References:

[1] Bfu, Schweiz 2014.

[2] Gschwind, Y.J., Bridenbaugh St. A. \& Kressig, R. W. (2013). Sturz im Alter. In Pinter, G. Likar et al. Geriatrische Notfallversorgung Strategien und Konzepte.

[3] Shumway-Cook, A., Brauer, S. \& Woollacott, M. (2000). Predicting the probability for falls in community-dwelling older adults using the Timed Up \& Go Test. Physical Therapy, 80(9).

[1] Kempen, G. I. J. M., Yardley, L., van Haastregt, J. C. M., Zijlstra, G. A. R., Beyer, N., Hauer, K. \& Todd, Chris (2008). The Short FES-I: a shortened version of the falls efficacy scale-international to assess fear of falling. Age and Ageing, 37(1)

Disclosure of Interest: None declared

DOI: 10.1136/annrheumdis-2017-eular.3774 